\title{
La labor del profesorado desde la reflexión pedagógica*
}

\author{
| Revista Colombiana \\ de Educación, N. 68. \\ de Educación, N. 68.
Primer semestre de 2015 , \\ Bogotá, Colombia.
}

\author{
//The Teaching Profession Seen \\ from Pedagogical Reflection
}
//O trabalho de professorado desde a reflexão pedagógica

\author{
Liliana Saavedra Rey** \\ Sneider Saavedra Rey***
}

Recibido: 29/08/2014 Evaluado: 02/03/2015

\begin{abstract}
* $\quad$ Artículo de reflexión derivado de la discusión sobre los resultados de la investigación Sentido de la evaluación docente a partir de la definición de la complejidad de las funciones del profesorado. Una aproximación a su resignificación pedagógica, presentada para optar al título de Maestría en Educación de la Universidad Pedagógica Nacional, la cual obtuvo distinción como tesis meritoria.

** Candidata a Doctora en Humanidades, humanismo y persona de la Universidad de San Buenaventura (sede Bogotá), Magíster en Educación, Especialista en Gerencia social de la Educación y Licenciada en Educación Preescolar de la Universidad Pedagógica Nacional. Coordinadora de investigaciones de la Facultad de Educación de la Universidad de San Buenaventura, Bogotá. Líder del grupo de investigación Tendencias Actuales en Educación y Pedagogía (TAEPE). Profesora de la Facultad de Educación de la Universidad Pedagógica Nacional. lilisaves2@yahoo.com

*** Magíster en Educación y Licenciado en Humanidades, Español y Lenguas Extranjeras de la Universidad Pedagógica Nacional. Profesor-investigador de la Maestría en Educación de la Universidad de San Buenaventura, Bogotá, perteneciente al grupo de investigación Tendencias Actuales en Educación y Pedagogía (TAEPE). Coordinador del área de Español y Literatura del colegio Gimnasio Los Portales. sneider201@hotmail.com
\end{abstract}

\section{Resumen}

A partir de reconocer los diversos campos de acción y funciones otorgadas al profesorado, especialmente por demandas externas a lo educativo y enmarcadas en el discurso neoliberal, se plantean cinco funciones interrelacionadas que definen su praxis desde la reflexión pedagógica: la didáctica como disciplina referente a la enseñanza que convierte el conocimiento teórico en formativo de acuerdo con las características del contexto; la formación humana como proceso interior y espiritual de autorrealización de las personas que trasciende la escolarización; la evaluación para comprender los procesos de enseñanzaaprendizaje y contribuir a la formación desde la comunicación auténtica; la participación en la construcción del currículo como interacción crítica entre los ideales, las propuestas y las prácticas educativas; y la transformación social como agente reflexivo, investigativo y político. El propósito de esta caracterización, de acuerdo con la investigación en que se fundamenta, es conceder identidad al profesorado mediante acciones que atañen a su formación pedagógica, como respuesta al desprestigio social y la desprofesionalización que enfrenta actualmente.

\section{Abstract}

From recognizing the variety of teaching profession's fields and functions -especially those demanded by external requests set by neoliberal age- this article proposes five correlated functions that define the teaching profession praxis based on pedagogical reflection: the didactics as a discipline about teaching that makes theoretical knowledge into an educational one, according to the characteristics of the context; human formation as an inner spiritual process of

\section{Palabras clave}

Didáctica, evaluación, formación humana, currículo, transformación social.

\section{Keywords}

Didactics, evaluation, human formation, curriculum, social transformation.

\section{Palavras chave}

Didática, avaliação, formação humana, currículo, transformação social. 
people's self-fulfillment going beyond schooling; evaluation to better comprehend the teaching-learning processes and contribute to formation from authentic communication, participation in curriculum design as a critical interaction among ideas, proposals and educational practices, and social transformation as a researcher and a reflective and political agent. The purpose of this characterization, according to the research it is based upon, is to develop a sense of identity in teachers through actions that refer to their pedagogical training, as a response to the discredit and the loss of professionalization that they face nowadays.

\section{Resumo}

Partindo de reconhecer os diversos campos de ação e funções otorgadas ao professorado especialmente pelas demandas externas ao educativo e enquadradas no discurso neoliberal, se planteiam cinco funções inter-relacionadas que definem sua práxis desde a reflexão pedagógica: a didática como disciplina referente ao ensino que transforma o conhecimento teórico em formativo de acordo com as características do contexto; a formação humana como processo interior e espiritual de auto-realização das pessoas que transcendem a escolarização; a avaliação para compreender os processos de ensino-aprendizagem e contribuir à formação desde a comunicação autentica; a participação na construção do currículo como interação critica entre os ideais, as propostas e as práticas educativas; e a transformação social como agente reflexivo, pesquisador e político. O propósito desta caracterização, de acordo com a pesquisa em que se fundamenta, e conceder identidade ao professorado por meio de ações que tem a ver com sua formação pedagógica, como resposta ao desprestigio social e a des-profissionalização que enfrenta atualmente.

La multiplicidad de funciones y ámbitos de trabajo del profesorado permite cuestionar si aquella actuación y la complejidad de esferas a las que atañe coinciden con su formación pedagógica y su consideración como agente de transformación social, o se limita a obligaciones de tipo contractual y demandas e intereses de otros sectores sociales ${ }^{1}$. Como afirma Laval (2004), la identidad escolar -y en ella, lo que se podría denominar la "identidad del profesorado"- está constantemente en crisis debido a las tensiones sociohistóricas que atraviesan su configuración, pues los imaginarios culturales y sociales del momento definen tanto sus finalidades políticas como sus premisas educativas y pedagógicas, las cuales confluyen en una relación subordinada de las instituciones y sus actores con respecto a lo que la sociedad

1 Para profundizar acerca de estas demandas sociales al profesorado, sus causas y consecuencias ver Saavedra Rey, L. (2008). La profesión docente, sus múltiples funciones y campos de acción: aproximación a la resignificación pedagógica. Pedagogía y Saberes, 29, 65-72. 
desea reproducir o transformar en un determinado momento histórico.

En la actualidad, los discursos de la globalización económica y el neoliberalismo, su racionalidad burocrática y complejo entramado ideológico, intervienen el sector educativo y la escuela. En el primer ámbito, con la disminución del Estado y la supresión de sus funciones sociales, la apertura de la educación pública al mercado y su privatización progresiva (Díaz Barriga, 2000; Díaz Borbón, 2003; Niño Zafra, 2004). En la escuela, exacerbando su crisis de identidad, tergiversada con los objetivos de cualquier organización empresarial (Laval, 2004; Santos Guerra, 2003), lo cual incide en su marginalidad social (Marcelo, 2001) como institución dependiente de las demandas del mercado. De hecho, como lo ha profundizado Barnett (2001), la idea actual de educación está determinada prioritariamente por el tipo de profesional que requiere el mundo laboral y no, como otrora, por los ideales instituidos por los centros educativos y sus maestros, en coherencia con su formación y experiencia pedagógicas.

Al entronizar los procesos de distribución, producción y consumo queda en evidencia, a la luz de los nuevos discursos, el carácter efímero de los conocimientos que circulan en la institución, las contradicciones de sus propósitos de formación y, en definitiva, su irrelevancia para preparar a las personas para la vida contemporánea (Pérez Gómez, 2004). Precisamente son ellas quienes se encuentran ante la fragmentación y la perplejidad propias de la era posmoderna que ha sustituido los valores e instituciones tradicionales por un "todo vale" basado en la inmediatez del intercambio económico. Esto ha causado el deterioro de las relaciones personales, la desconfianza respecto del valor de los saberes que circulan en la escuela, la banalización de la cultura que ella transmite (ahora subordinada a las exigencias del mercado y a su uso como espectáculo) y, en el tema específico de este artículo, la pérdida de autoridad y el desprestigio del profesorado, ahora acusado de "embridar el espíritu y sana rebeldía de los estudiantes" (Vargas Llosa, 2012, p. 85). A esto se suma su estado de desprofesionalización fundamentado en las políticas educativas que generan responsabilidades desbordantes, exámenes y seguimientos de carácter técnico, el desconocimiento de la autonomía y el profesionalismo de su ejercicio, bajos ingresos económicos (Imbernón, 1994; Marcelo, 2001) y la posibilidad de que diversos profesionales o técnicos ajenos a lo pedagógico ejerzan como docentes carentes de formación para hacerlo, más allá, quizá, de algún curso "express" de pedagogía.

Desde las mismas políticas transnacionales de organismos como el BM, el FMI, el BID, la OCDE o el Preal, y sus sucedáneos nacionales, se concibe la educación en términos de rentabilidad, en detrimento de sus ideales de formación (Díaz 
Barriga, 2001). Así, el espacio escolar se ha convertido en un híbrido de aspectos propios del sector financiero y los sistemas burocráticos en cuanto a su organización, gerencia y administración (Laval, 2004; Santos Guerra, 2003). Esto genera riesgos para la formación del profesorado, que puede reducirse a la producción en masa de docentes que, desde la flexibilidad demandada por el mismo sistema, se articulan al mundo laboral dispuestos a adaptarse a sus instituciones y puestos de trabajo, así esto implique la suplantación del sentido pedagógico de dicha labor con actividades de carácter técnico, administrativo, eficientista y de gestión, que evidentemente alejan la actuación del profesorado de su formación como profesional de la educación debido a su pérdida de autonomía (Hernández y Sancho, 1999).

Como respuesta a este contexto en el que se ha instituido el "malestar docente", esa incomodidad del profesorado por las múltiples funciones que desbordan su labor educativa (Imbernón, 1994), este artículo de reflexión presenta cinco funciones ${ }^{2}$ interrelacionadas y constitutivas de la labor del profesorado desde su comprensión pedagógica, de acuerdo con los resultados de la investigación citada. De allí se derivan acciones acordes con la formación de los maestros y las demandas educativas a las que pueden y deben dar respuesta, referidas a la complejidad del proceso de formación humana. Así, subyace a esta propuesta la construcción de esa "otra escuela y otra pedagogía para la sociedad del conocimiento", en cuya formulación "se requiere repensar la función docente" (Pérez Gómez, 2004, p. 96) en el reconocimiento de su valor pedagógico, didáctico, formativo, intelectual, cultural, social e histórico.

\section{El profesor como didacta}

Como parte de su formación y ejercicio profesional, la didáctica constituye un campo de acción fundamental para los profesores en tanto disciplina que analiza prácticas educativas específicas con el fin de potenciar los aprendizajes desde la enseñanza, pues demanda del profesorado un estudio riguroso de

2 El concepto de función (para determinar las que desde lo pedagógico atañen al profesorado) se utilizó en la investigación en su sentido prístino, como acción que corresponde realizar a alguna persona. De cualquier manera, se ha omitido su uso en este artículo, con esta excepción aclaratoria, debido al lastre ideológico que permitiría contradicciones con respecto a la fundamentación pedagógica de cada uno de los ámbitos presentados. En su lugar, se utilizan de manera aleatoria términos como "formación", "labor", "reflexión y acción" o "campo de acción" del profesorado. 
las características y condiciones de los participantes, los contextos y los procesos del acto de enseñar, con el fin de desarrollar prácticas que contribuyan a alcanzar sus propósitos formativos $y$, a la vez, establecer un marco normativo para la acción educativa en otros contextos.

Esta conciencia de lo práctico y su consecuente divulgación con fines educativos es el material de cualquier tratamiento didáctico, como conocimiento específico de la formación pedagógica del profesorado. Toda teoría sobre la educación, además de los aportes que recibe de la psicología, la antropología, la sociología, la epistemología o cualquier otra disciplina, se articula a la didáctica cuando deviene una acción intencionalmente educativa, cuando se hace conocimiento aplicable y comprensible que permite la interpretación de la práctica y proyecta la actuación del maestro.

Esta "transformación del conocimiento científico en conocimiento educativo", en palabras de Álvarez Méndez (2000), se fundamenta en que el didacta sabe lo que enseña (componente epistemológico), investiga y conoce los procesos de enseñanza-aprendizaje (componente psicopedagógico) y posibilita la creación de situaciones apropiadas para el aprendizaje teniendo en cuenta la incidencia de contextos sociales más amplios (componente didáctico). Esto remite al planteamiento de Klafki cuando establece la diferencia entre Inhalt (contenido) y Gehalt (contenido formativo), entre los cuales trabajan el didacta $y$ el educador explotando aquello verdaderamente importante y pertinente (lo formativo) que hay en un contenido para hacerlo parte de la enseñanza (citado por Runge, 2008). Es más, tal contenido formativo no puede confundirse como uno meramente derivado de la disciplina, pues su génesis se sitúa en una antropología del conocimiento y una epistemología sobre su construcción, mediada entre el sujeto y el objeto (Perafán, 2013). Esto ha llevado a Chevallard (1997) a proponer el concepto de 'transposición didáctica', para distinguir los saberes disciplinares de aquellos propios de la enseñanza, direccionados por una intencionalidad educativa propia del conocimiento pedagógico.

Estas características y propósitos disciplinares mantienen el espíritu con el cual Comenio formuló la didáctica en el siglo XVII, como "artificio universal para enseñar todo a todos" (1638/2010, p. 33). Si bien sus antecedentes pueden buscarse en la Grecia clásica y los diálogos socráticos, y su nacimiento en De Magistro de San Agustín en la Edad Media, es indudable la influencia de la Didáctica Magna para concretar una teoría sobre el arte de enseñar. Es más, es el contexto europeo de la época, configurado por la Reforma y la Contrarreforma y las propuestas del humanismo desarrolladas desde el inicio del Renacimiento, el cual, en voz de autores como Montaigne, Rabelais, Rotterdam o Vives, plantea nuevos horizontes en la instrucción 
impartida en la escuela moderna. De acuerdo con Hamilton (1993), este periodo desarrolla una relación más elaborada entre pedagogía y didáctica a través de un "giro instructivo" que resalta el tema de la enseñanza, más que el aprendizaje.

A esta disciplina incipiente se sumaría una larga lista de pensadores, como Rousseau, Herbart, Pestalozzi, Dewey, Montesori, Decroly, entre otros, siempre atentos al carácter formativo que recoge el origen etimológico de la didáctica (didaktika), derivado del verbo 'enseñar' (didaskao). De ahí que las diversas definiciones de esta disciplina, en tanto arte de enseñar todo a todos (Comenio); catálogo de procedimientos o máximas que asignan al docente una clara centralidad en el arte de la enseñanza (Ratke); estudio de la tríada didáctica constituida por el sujeto que conoce, el objeto de conocimiento y el maestro (Herbart), o teoría de la adquisición de lo que posee valor formativo (Willman), se articulen en su consideración como campo de conocimiento construido desde la teoría y la práctica para desarrollar acciones intencionadas y organizadas que posibiliten el aprendizaje, de acuerdo con una concepción educativa basada en la reflexión pedagógica.

\section{La formación humana, más allá de la escolarización}

Los propósitos de la educación, sin embargo, no se circunscriben a la instrucción y su hipotética generación de aprendizajes, sino que trascienden la formación humana. Desde esta comprensión, la respuesta sobre quién es el ser humano, en tanto ser histórico, singular, concreto y trascendente, y no simplemente como abstracción o idealización, sustentan toda praxis pedagógica (Londoño, 2013).

Como bien lo plantean Flórez y Vivas (2007), más allá de las divergencias en torno a los propósitos de la educación de acuerdo con diversas tendencias y discusiones pedagógicas, ha pervivido la concepción de formación (building) como su objetivo por excelencia, entendida como "un proceso de humanización que conduce a niveles superiores de autonomía, inteligencia y solidaridad" (Flórez y Vivas, 2007, p. 166). Es más, estos autores, en el reconocimiento de la tradición pedagógica desde Comenio, plantean que la formación podría unificar el campo conceptual de la pedagogía y sus fines educativos debido a su importancia para la humanidad y sus sociedades. 
Los conocimientos, aprendizajes y habilidades constituyen apenas medios para formarse como ser humano. La condición de la existencia humana es formarse, integrarse, convertirse en un ser espiritual capaz de romper con lo inmediato y lo particular, y ascender a la universalidad mediante el trabajo compartido y la reflexión filosófica sobre sus propias raíces. Formar a un individuo es facilitarle que asuma, en su vida, su propia dirección racional, reconociendo a los otros el mismo derecho y la misma dignidad (Flórez y Vivas, 2007, p. 167).

Ya en un trabajo anterior Flórez (2005) planteaba, de acuerdo con Humboldt, las diferencias entre cultura y formación, reconociendo en el segundo concepto algo más elevado y más propio del interior del ser humano, dado que "en la formación uno se apropia por entero y perdurablemente de aquello en lo cual y por lo cual uno se forma [...] que nunca se olvida y nunca pierde su función" (Flórez, 2005, p. 215). También señalaba que lo esencial para la persona en su formación es "convertirse en un ser espiritual capaz de asumir sus propios deseos, necesidades e intereses privados y ascender a la generalidad, a la universalidad espiritual, a través del trabajo y de la reflexión teórica hasta reconciliarse consigo mismo". Por su parte, la educación, emparentada con el devenir cultural, se queda en el cultivo y desarrollo de aptitudes y habilidades, pero no trasciende necesariamente a los procesos interiores y espirituales de las personas.

En este sentido, Garcés y Runge (2011) precisan que "la formación denota un devenir y una autorrealización constante" (Garcés \& Runge, 2011), pues mientras lo educativo es una práctica externa al ser humano, una interacción entre dos o más actores que se preguntan por cómo direccionar el uno al otro, la formación se plantea el qué y el para qué. Para estos autores, igual que para Humboldt y Flórez, ese rasgo "formable" es parte inmanente del ser humano en cuanto disposición para el desarrollo y crecimiento de todos sus aspectos (corporales, espirituales, afectivos). Así, reconocen que el ser humano no nace determinado sino que se determina y se forma en sus múltiples dimensiones como parte de su misma constitución como persona.

Este concepto de formación como autorrealización trasciende la escolarización que, como bien lo plantea Kemmis (1988), se convierte en la "cosificación" del sistema educativo de masas que circunscribe el acto de educar a sus aspectos técnicos para el ejercicio de ciertas habilidades y la acumulación de ciertos contenidos mínimos para la subsistencia laboral y social. 
De esta manera, retorna a los clásicos de la pedagogía, como Kant (2008) y Herbart (1990), para quienes la formación comprende, y a la vez supera, el cuidado (alimentación, conservación), la disciplina (crianza) y la instrucción, como tareas propias de cada individuo, desde su interioridad, para lograr su formación espiritual.

Esto se erige como respuesta pedagógica a las exigencias laborales de la actualidad y la subordinación de la escuela a estas demandas, mediante la valoración de un mundo de la vida con otras posibilidades de formación, más allá del intercambio económico o la inserción al mundo del trabajo como formas de realización personal y social para los seres humanos (Barnet, 2001). Por esta razón, es preciso desarrollar:

... planes de acción pedagógico-social y también escolar, que desmitifiquen el valor del trabajo productivo como único medio de realización personal. La educación de la sensibilidad y de las capacidades humanas no relacionadas con la dimensión productiva deben considerarse objetivos pedagógicos básicos (Martínez, 1998, p. 23).

La reflexión y acción pedagógicas, desde esta perspectiva, no se limitan a la mecanización y aplicación de cierto conocimiento en concordancia con el proyecto laboral de los individuos -la promoción del capital humano en términos biopolíticos- sino que propende por la formación del ser humano, el enriquecimiento de la persona para sí misma, para los demás y para su comunidad, dándole validez y trascendencia, ya no al proyecto laboral entronizado por la escuela, sino a su propio, único e irrepetible proyecto de vida.

\section{La evaluación para la comprensión, más allá de la calificación}

A pesar de las connotaciones de su contexto de origen (la industria textil) y sus objetivos de control de la productividad tanto en el mundo laboral como en su transposición a los ámbitos educativos -o precisamente por dicha relevancia dentro del discurso actual de la calidad- la evaluación se constituye en un ámbito de reflexión y acción fundamental para el profesorado. Evidentemente, como estrategia de intervención en todos los niveles del sistema educativo, su comprensión modela la conciencia del 
maestro y advierte sobre las repercusiones ideológicas y formativas del acto de educar como parte de un sistema político intencionado que trasciende los límites nacionales. $\mathrm{Su}$ abordaje expone las cortapisas del sistema de escolarización, independientemente de las intenciones loables de los procesos formativos. Asimismo, promueve el reconocimiento de maneras alternativas de evaluar, aprovechando el foco de interés que genera socialmente en cuanto a aprobación y certificación.

En la actualidad, las prácticas de evaluación dificilmente buscan comprender los procesos educativos para enriquecerlos, en detrimento de la complejidad de la formación abordada en el apartado anterior. Por el contrario, pervive una evaluación educativa de carácter instrumental, basada en la teoría de la administración científica del trabajo de Taylor, los test de rendimiento de la psicometría, los objetivos conductuales de Bloom, las tecnologías educativas $y$, en la actualidad, la racionalidad neoliberal (Niño Zafra, 2006). Sin sentido pedagógico debido a su contexto de origen y uso estratégico, se circunscribe la evaluación a la calificación, imponiendo criterios que tienen graves implicaciones para la formación: lo humano ha sido desplazado por el adiestramiento técnico; la experiencia por la puntuación; las personas son tasadas según su rendimiento escolar y normalizadas de acuerdo con criterios estandarizados que fomentan un currículo y un pensamiento únicos. La evaluación se convierte entonces en instrumento que se justifica en su eficiencia, eficacia y objetividad, así como en la caracterización del conocimiento y la formación como algo observable, medible y cuantificable.

De esta manera, se omite el carácter formador que podría tener la evaluación y se asume como "comprobación de aprendizaje" y "medio de control social" (Santos Guerra, 1998, p. 18) al establecer un sistema de selección que busca garantizar tanto el éxito como el fracaso académico y laboral. Esto se desarrolla mediante la comprobación de saberes en pruebas estandarizadas que son utilizadas como garantía social de acreditación e indicador cuantificable para la toma de decisiones administrativas en el sistema educativo.

Reconocidos su origen, instauración y naturalización dentro de los procesos de enseñanza-aprendizaje, la evaluación se constituye en otro campo fundamental para la acción y la reflexión del profesorado, tal como lo han planteado, entre otros autores, Pérez Gómez (2004), Álvarez Méndez (2005), Díaz Barriga (2000), Litwin (1998), Santos Guerra (1998) o Niño Zafra (2006). En tal dirección, se considera como "componente didáctico" (Litwin, 1998) porque profundiza en los procesos educativos para comprenderlos y tomar decisiones que favorezcan la enseñanza; es decir, "permite definir, seleccionar, diseñar, recoger, analizar, interpretar $y$ 
usar la información para incrementar el aprendizaje" (Brown \& Glasner, 2003). En consecuencia, esta evaluación se caracteriza por ser flexible, negociada, intersubjetiva y orientada a la evolución integral de todos sus participantes. "La evaluación para valorar, la evaluación para mejorar el aprendizaje, la evaluación como contenido a aprender para su utilización futura" (Bordas \& Cabrera, 2001, p. 26), la cual plantea una oportunidad para construir conocimiento demostrando lo que los estudiantes y maestros hacen y aprenden en el aula, así como para enriquecer la formación desde la apropiación significativa y responsable de dicho proceso, abordando, entre otros aspectos, la reflexión, la autonomía, el respeto y el reconocimiento del otro: maestro, par o estudiante.

Desde esta perspectiva, la evaluación es una actividad que configura la comprensión del hecho educativo y, por medio de ella, mejora el quehacer docente y el ejercicio estudiantil. El estudiante aprende y se forma por medio de la realimentación que se genera en el diálogo argumentado y crítico con su profesor, mientras él aprende y se forma en tanto reconoce nuevos horizontes de sentido para su práctica docente. En esta acción comunicativa, los sujetos trabajan de manera argumentada para construir conocimiento; ambos buscan aprender mediante el reconocimiento de dificultades por superar, el modo de resolverlas y las estrategias que se ponen en juego. Su base epistemológica es la racionalidad práctica y crítica caracterizada por el juicio ético con el que se actúa en determinada situación educativa reconociendo su trascendencia con respecto a la transformación social. Esto contribuye a que la evaluación se constituya en "actividad crítica de aprendizaje" (Álvarez Méndez, 2005, p. 77) y, así, lleve a todos a construir conocimiento, a apropiarse del mundo de un modo reflexivo y crítico, y no a perpetuar los fracasos escolares en una instancia final, como apéndice del proceso.

De esta manera los procesos evaluativos se convierten en la práctica institucional que acompaña de modo permanente y continuo la acción didáctica y el desarrollo curricular, con el fin de establecer sus falencias, potencialidades y demás comprensiones pertinentes formativamente, más allá de los dualismos valorativos. En consecuencia, la información que recoge sustenta una toma de decisiones respecto a la praxis didáctica y curricular, en la búsqueda de los propósitos formativos establecidos por la comunidad educativa. Así, la evaluación se constituye en componente didáctico en cuanto atiende a las 
condiciones y contingencias del proceso de enseñanza-aprendizaje para su mejoramiento. Además, accede a las prácticas de certificación institucional, junto a la calificación y la medición, replanteándolas en el marco de la formación humana.

\section{La construcción del currículo}

Como afirma McDonald, "la enseñanza no es la aplicación del currículo, sino la continua invención, reinvención e improvisación del currículo" (citado por Contreras, 1997, p. 85). Es precisamente en dicha construcción, no en la ejecución de algo preestablecido sin atender a las características de los educandos y contextos específicos, en la que el profesorado participa como agente fundamental de los procesos de formación. En este sentido, resulta imprescindible reconocer que la constitución del currículo confiere un modo particular de asumir la educación en cuanto propósitos por realizar, interacción dentro y fuera del aula, concepción del conocimiento y sus intencionalidades, caracterización del estudiante y de la escuela, elementos o procesos por evaluar, entre otros aspectos que, concretando una visión sociopolítica específica sobre la educación, repercuten en los presupuestos pedagógicos, políticos y sociales ligados a sus prácticas (Posner, 2005).

Este concepto de currículum como "construcción cultural" (Grundy, 1991), más allá de una entidad abstracta o anquilosada, pone de manifiesto la importancia del contexto y la caracterización de una reflexión pedagógica en la acción para la formación estudiantil. Sin embargo, su origen remite a la enseñanza escolar como consecuencia del crecimiento social que demandaba la planificación y constitución de sistemas y centros escolares eficientes, encaminados a la consecución de los objetivos políticos de la educación de masas. Por ello, no se originó a partir de un interés meramente académico, sino para el tratamiento sistemático y fundamentado a las decisiones relativas a qué y cómo enseñar en los Estados Unidos (Contreras, 1997), de acuerdo con la competitividad que este país quería alcanzar en lo referente al conocimiento científico, sobre todo en su competencia en la carrera espacial. Esto explica su énfasis en la gestión de los sistemas escolares: el establecimiento de medios y procedimientos para alcanzar ciertos objetivos educativos orientados por el Estado.

No obstante, el desarrollo curricular estableció una línea de reflexión pedagógica afín a los intereses del pensamiento didáctico de Europa continental (Hamilton, 1999), pues no podía obviar el estudio de las prácticas, los contenidos y los propósitos de la enseñanza. Esto hace que pedagogos como Klafki (1986, citado por Runge, 2008), examinando el traslado del concepto a Alemania, país de amplia tradición didáctica, considere que tanto 
la didáctica como el currículo se ocupan de un mismo objeto de estudio: la enseñanza.

A pesar de tal acercamiento, no se puede olvidar que el currículo emergió como práctica de diseño y regulación de los centros escolares para hacer efectivo el tránsito de las políticas al aula de clase, lo cual tergiversó el papel del maestro definido por la didáctica como sujeto reflexivo en torno a los procesos de enseñanza-aprendizaje. Esta situación relegó al profesorado a una actividad técnica de seguimiento de instrucciones para alcanzar objetivos trazados desde otros intereses sociales y enmarcados en el ámbito institucional. Es más, dentro de esta misma crítica, el objetivo del currículo de reproducir una ideología o identidad particular (Apple, 2008) plantea un cuestionamiento para los maestros, quienes pueden obviar su discusión por su pertenencia a un campo ajeno al ejercicio pedagógico o, por el contrario, trabajar tal implicación ideológica en términos formativos.

Esta crítica a la racionalidad técnica de la teoría curricular remitió a un espacio fértil de discusión en torno a las perspectivas de autores como Grundy (1991), Kemmis (1988), Stenhouse (1987) o Apple (2008), y permitió la apertura del currículo a su dimensión práctica, de acción en las escuelas, y su derivado alcance crítico en estos procesos de formación. En este sentido, Posner (2005) afirma que "el primer paso para una comprensión profunda es considerar el currículo como el producto de un grupo de personas que enfrentan una serie de decisiones políticas, técnicas y económicas, guiadas y limitadas por su propio sistema de creencias personales" (2005, p. 35). Esto remite a no concebir el currículo como algo inmanente, que aparece de forma "natural" en la institución, sino que depende del contexto, las concepciones e intencionalidades de quienes lo formulan y, en general, de diversos condicionamientos, intereses y necesidades que lo gestan en un momento específico.

A partir de estas ideas iniciales de currículo (que se configura entre la teoría y la práctica real, contextual, específica), es posible aseverar la definición que Stenhouse da al concepto: "todos los curricula son verificaciones hipotéticas acerca de la naturaleza del conocimiento y del aprendizaje", pues propende por "la interacción crítica entre ideas y propuestas educativas y la interacción crítica entre estas propuestas y la práctica cotidiana" (Stenhouse, 1987, p. 101). Así, el currículo expresa, en definitiva, el horizonte educativo de la institución y, por ende, la concepción de educación que la soporta: qué, cómo y para qué 
se aprende; cómo se desarrolla este aprendizaje, quiénes lo realizan, cómo lo afecta el contexto, cuáles son las condiciones para que se dé, entre otros interrogantes que suscitan el andamiaje de cada práctica educativa.

Entendido como "el intento de comunicar los principios esenciales de una propuesta educativa, de tal forma, que quede abierta al escrutinio crítico y pueda ser traducida efectivamente a la práctica" (Stenhouse, 1987, p. 101), la construcción del currículo convoca por definición al maestro pues lo que se constituye es el escenario de su praxis. Así, su estudio resulta fundamental en su formación y actuación, pues refiere la articulación entre la teoría y la práctica del profesorado, poniendo en consideración el conocimiento pertinente y las formas pedagógicas válidas de acuerdo con los elementos contextuales específicos de cada proceso.

\section{El profesor como investigador y actor político}

El profesor no se queda como didacta y formador de seres humanos limitado a las coordenadas espaciales y temporales de su aula o institución. Al estar propiciando una confrontación con el conocimiento a partir del mundo de la vida, es necesariamente un sujeto que reflexiona sobre la realidad circundante en su contexto social más cercano (su barrio, su localidad, su ciudad, su región, su país) y, de manera simultánea o progresiva, sobre contextos sociales más amplios que engloban la realidad política, económica y cultural de los seres humanos en el mundo. Así, todo maestro deviene actor político al convertir su ejercicio reflexivo, no en un solipsismo intelectual, sino en "una ocupación socialmente encomendada y que le responsabiliza públicamente" (Contreras, 1997, p. 52).

Aunque parezca lugar común, en manos del profesorado se encuentra la responsabilidad sobre ciudadanos presentes y futuros, lo que "supone un compromiso social y ético que procura transformaciones de carácter personal como comunitario" (Martínez, 1998, p. 9); un compromiso político desde su sentido más prístino, como agente activo en la toma de decisiones que se constituyan en aporte para su comunidad, para la construcción de la sociedad. En palabras de Freire (2006), se puede decir que enseñar exige comprender que la educación es una forma de intervención en el mundo que, más allá de los contenidos, "implica tanto el esfuerzo de reproducción de la ideología dominante como su desenmascaramiento" (Freire, 2006, p. 95). Estos objetivos explican el carácter ideológico de toda acción educativa y exigen del profesorado una actitud crítica para generar propuestas de transformación social. Por consiguiente, su compromiso pedagógico demanda 
del profesor ser un investigador que genere cambios en su práctica cotidiana $y$, por ende, una actitud política en la que defina su posición con respecto a la educación, la pedagogía, sus estudiantes, la cultura del conocimiento, las políticas educativas y la sociedad.

Esta idea del profesor como profesional reflexivo considera el proceso educativo como fenómeno de estudio. De hecho, Schon propone una reflexión-en-la-acción tendiente a "cuestionar la definición de su tarea, las teorías-en-la-acción de las que parte y las medidas de cumplimiento por las que es controlado [...]" (citado por Contreras, 1997, p. 80), lo cual lleva a descubrir los valores y técnicas presentes en el conocimiento organizacional. Así, el profesional no se constituye en ejecutor de programas sino que, al reflexionar-en-la-acción, transforma el proceso educativo que está desarrollando mediante su constante valoración, consolidando su labor profesional.

Otros teóricos, como Stenhouse (1987), engloban esta actitud en la concepción del profesor como investigador; definición que enfatiza el hecho de que este experimente con su propia práctica con el fin de mejorar las cualidades de los procesos de formación y, junto a ellos, reinventar y fortalecer los elementos y criterios del currículo. En esta misma línea conceptual, se puede mencionar a Giroux (1997) y su propuesta del profesor como intelectual crítico, en la cual se acentúa la obligación de hacer problemáticos los presupuestos que sustentan las prácticas escolares y, en general, el discurso social. "Enseño porque busco, porque indagué, porque indago y me indago" afirma Freire (2006, p. 30), lo cual aclara que el profesor no debe constituirse en investigador, pues esta no es una calidad externa a su ejercicio, sino que, en tanto profesor, es investigador de la educación. Es precisamente de este compromiso que parte su participación fuera del aula y que lo convierte, inevitablemente, en agente político en contextos sociales más amplios como aperturas fundamentales para su formación.

Como lo afirma Gutiérrez (1998), la función prioritaria de la escuela, más allá de cualquier aprendizaje, es su función sociopolítica, pues desde allí el maestro inculca en sus estudiantes diversos discursos, ordenamientos, conductas y valores de su cultura para lograr insertarlo en la vida social. Esta acción se puede considerar una inyección ideológica hacia espacios que trascienden el aula o la institución educativa y, por lo tanto, se constituye en una actividad política, ya que da prevalencia a 
determinadas creencias o ideologías sobre otras. Nuevamente con Freire (2006), el profesor tiene como exigencia reconocer que la educación es ideológica. Es más, la misma observación demuestra que sus componentes fundamentales son la pedagogía y la política, pues el profesor es un agente ideológico que encauza un discurso de formación de sujetos. "Todos [...] hacemos política permanentemente, pero el educador la hace de una manera privilegiada, ya que el estado pone a sus órdenes un determinado número de futuros ciudadanos para que los 'socialice', es decir, para que los politice" (Gutiérrez, 1988, p. 25).

Por esta razón, toda palabra, acción o enseñanza del maestro es un ejercicio político. Su propia formación y experiencia como pedagogo (crítico, reflexivo e investigador) lo consolidan como pensador sobre la humanidad y la cultura que puede formular propuestas explícitas para la transformación social. Esta politicidad de la educación genera en el profesorado la disyuntiva de apoyar e impulsar ciertas ideas y valores, $\mathrm{u}$ omitirlos; cuestionando a los maestros acerca del porqué ciertos saberes resultan válidos y otros se anulan de acuerdo con los intereses de determinados sectores sociales (Apple, 2010).

Su reflexión dentro del aula, su actitud investigativa sobre su práctica y su discurso ideológico evidencian el ámbito más amplio de su labor y su participación política como derecho y deber ciudadano. No obstante, su transmisión de valores y discursos a la niñez y la juventud, le confiere su responsabilidad política en cuanto participante activo en la construcción de la sociedad.

\section{Referencias bibliográficas}

Álvarez Méndez, J. (2000). Didáctica, currículo y evaluación. Ensayos sobre cuestiones didácticas. Madrid: Miño y Dávila.

Álvarez Méndez, J. (2003) La evaluación educativa en una perspectiva crítica: dilemas prácticos. Bogotá: Universidad Pedagógica Nacional.

Álvarez Méndez, J. (2005). Evaluar para conocer, examinar para excluir. Madrid: Morata.

Apple, M. (2008). Ideología y currículo. Madrid: Akal.

Barnett, R. (2001). Los límites de la competencia: el conocimiento, la educación superior y la sociedad. Barcelona: Gedisa.

Brown, S. \& Glasner, A. (2003). Evaluar en la universidad. Problemas y nuevos enfoques. Madrid: Narcea.

Camilloni, A. (2008). Los profesores y el saber didáctico. En: A. Camilloni (ed.) El saber didáctico (pp. 41-60) Buenos Aires: Paidós.

Contreras, D. (1997). La autonomía del profesorado. Madrid: Morata.

Díaz Barriga, A. (1997). Didáctica y currículum. México D. F.: Paidós. 
Díaz Barriga, A. (2000) Evaluar lo académico. Organismos internacionales, nuevas reglas y desafíos. En: T. Pacheco y A. Díaz Barriga (ed.) Evaluación académica. México: Fondo de Cultura Económica.

Díaz Borbón, R. (2003) Políticas educativas y protagonismo social de la educación pública. Opciones Pedagógicas, 28, 14-48.

Dilthey, W. (1940). Fundamentos de un sistema de pedagogía. Buenos Aires: Losada.

Durkheim, É. (2001). Educación y sociología. México: Coyoacán.

Eisner, E. (2002). La escuela que necesitamos. Ensayos personales. Buenos Aires: Amorrortu.

Fernández Sierra, J. (1994). Evaluación del currículum: perspectivas curriculares y enfoques en su evaluación. En: F. Angulo y N. Blanco (ed.). Teoría y desarrollo del currículum (pp. 297-312). Málaga: Aljibe.

Flórez, R. (2005). Pedagogía del conocimiento. Bogotá: McGraw-Hill.

Flórez R. y Vivas, M. (2007, enero-abril). La formación como principio y fin de la acción pedagógica. En: Revista Educación y Pedagogía, 9 (47), 165-173.

Freire, Paulo. (2006). Pedagogía de la autonomía. Saberes necesarios para la práctica educativa. México D. F.: Siglo XXI.

Garcés, J. \& Runge, A. (2011) Educabilidad, formación y antropología pedagógica: repensar la educabilidad a la luz de la tradición pedagógica alemana. En: Revista Científica Guillermo de Ockham, 9 (2), 13-25.

Giroux, H. (1997). Los profesores como intelectuales. Hacia una pedagogía crítica del aprendizaje. Barcelona: Paidós/M.E.C.

Grundy, S. (1991). Producto o praxis del curriculum. Madrid: Morata.

Gutiérrez, F. (1988). Educación como praxis política. México D. F.: Siglo XIX.

Herbart, J. F. (1990). Pedagogía general. Barcelona: Ediciones de la Lectura.

Hernández, F. \& Sancho, J. (1999). Para enseñar no basta con saber la asignatura. Barcelona: Paidós.

Kant, I. (2008) Sobre pedagogía. Córdoba: Encuentro.

Laval, C. (2004). La escuela no es empresa. El ataque neoliberal a la enseñanza pública. Barcelona: Paidós.

Litwin, E. et ál. (1998). La evaluación de los aprendizajes en el debate didáctico contemporáneo. Buenos Aires: Paidós 
Litwin, E. (2008). El oficio de enseñar. Condiciones y contextos. Buenos Aires: Paidós.

Marcelo, C. (ed.) (2001). La función docente. Madrid: Síntesis.

Martínez, M. (1998) El contrato moral del profesorado. Condiciones para una nueva escuela. Bilbao: Desclée de Brouwer.

Niño Zafra, L. (2004). Políticas educativas y evaluación docente: medición, objetividad y control para la exclusión. En: L. Niño Zafra (ed.). Encuentro internacional sobre políticas, investigaciones y experiencias en evaluación educativa: consecuencias para la educación (pp. 53-65) Bogotá: Icfes.

Niño Zafra, L. (ed.). (2007). Políticas educativas. Evaluación y metaevaluación. Bogotá: Universidad Pedagógica Nacional.

Niño Zafra, L. (2010). De la perspectiva instrumental a la perspectiva crítica. Pedagogía, currículo y evaluación. Bogotá: Universidad Pedagógica Nacional, Colciencias.

Pérez Gómez, A. (2004). La construcción del sujeto global. Opciones Pedagógicas, 29 y 30, 77-100.
Posner, G. (2005). Análisis del currículo. México D. F.: McGraw-Hill.

Runge Peña, A. (2008). Ensayos sobre pedagogía alemana. Bogotá: Universidad Pedagógica Nacional.

Saavedra Rey, L. (2008) La profesión docente, sus múltiples funciones y campos de acción: una aproximación a su resignificación pedagógica. Pedagogía y Saberes, 29, 65- 72.

Santos Guerra, M. (1998). Evaluar es comprender. Buenos Aires: Magisterio del Río de la Plata.

Santos Guerra, M. (1999). Crítica de la eficiencia y eficacia de la calidad de la crítica: lo verdadero, lo verosímil y lo verificable en el análisis de las instituciones educativas. En: J. Angulo Rasco (ed.) Escuela pública y sociedad neoliberal. (pp. 83-112). Madrid: Miño y Dávila.

Santos Guerra, M. (2003). Trampas en educación. El discurso sobre la calidad. Madrid: La Muralla.

Stenhouse, L. (1987). La investigación como base de la enseñanza. Morata: Madrid.

Vargas Llosa, Mario. (2012). La civilización del espectáculo. Alfaguara: Bogotá.

Villardón, L. (2006). Evaluación del aprendizaje para promover el desarrollo por competencias. Educatio Siglo XXI, 24, 57- 76. 